\title{
CIÊNCIA CIDADÃ E SUA CONTRIBUIÇÃO NA PROTEÇÃO E CONSERVAÇÃO DA BIODIVERSIDADE NA RESERVA DA BIOSFERA DO PANTANAL
}

\author{
Simone Mamede ${ }^{1}$ \\ Maristela Benites ${ }^{2}$ \\ Cleber José Rodrigues Alho ${ }^{3}$
}

Resumo: Ciência cidadã representa relevante aporte ao conhecimento científico e à conservação ambiental a partir do envolvimento dos cidadãos. Instituído como Reserva da Biosfera, o Pantanal atrai pessoas do mundo inteiro que buscam ter experiências com a natureza, sendo esta uma oportunidade para conhecimento, conservação e educação ambiental. Neste trabalho avaliamos como a ciência cidadã e seus instrumentos têm contribuído para a conservação da biodiversidade do Pantanal. Foram analisadas ações de ciência cidadã, tais como eventos ecoturísticos para observação de aves e as plataformas colaborativas: Biofaces, Wikiaves, eBird e Táxeus, num recorte geográfico envolvendo a planície pantaneira e os planaltos adjacentes, no período de 2013 a 2015. Os resultados apontam evidências do comprometimento e apoio de cidadãos cientistas na geração de conhecimento sobre a biodiversidade regional vinculados ao exercício de cidadania e à transformação crítica de pensamentos e conduta.

Palavras-chave: Birdwatching, Educação Ambiental, Engajamento Social, Vivências na Natureza.

\footnotetext{
${ }^{1}$ Instituto Mamede de Pesquisa Ambiental e Ecoturismo, Campo Grande-MS

Uniderp, Programa de Pós-Graduação em Meio Ambiente e Desenvolvimento Regional, Campo GrandeMS. E-mail: simone.mamede1@gmail.com

2 Instituto Mamede de Pesquisa Ambiental e Ecoturismo, Campo Grande-MS

Uniderp, Programa de Pós-Graduação em Meio Ambiente e Desenvolvimento Regional, Campo GrandeMS. E-mail: maris.bentes@gmail.com

${ }^{3}$ Uniderp, Programa de Pós-Graduação em Meio Ambiente e Desenvolvimento Regional, Campo GrandeMS. E-mail: alho@unb.br
} 


\section{Introdução}

O Pantanal foi reconhecido pela UNESCO (Organização das Nações Unidas para a Educação, Ciência e Cultura) como Reserva da Biosfera no ano de 2000. Esse modelo de área protegida celebrada pelo Programa Intergovernamental "O homem e a Biosfera, Man and the Biosphere Programme - MAB" contempla funções básicas como a conservação da biodiversidade e a ampliação do conhecimento a ela relacionada, servindo de impulso à sustentabilidade ambiental e socioeconômica e de apoio à compreensão e melhoria das relações entre as comunidades e o seu meio natural. Esse formato de área protegida estabelecido pela UNESCO, e da qual - Brasil participa, é reconhecido pelo Sistema Nacional de Unidades de Conservação da Natureza - SNUC (Lei federal no 9.985/2000).

A Reserva da Biosfera do Pantanal compreende uma área de aproximadamente 25 milhões de hectares, com 15 áreas-núcleo que incluem os Parques Nacionais: do Pantanal (MT), da Chapada dos Guimarães (MT), das Emas (GO/MS) e da Serra da Bodoquena (MS); os Parques Estaduais da Serra de Santa Bárbara (MT), das Nascentes do Rio Taquari (MS) e do Pantanal do Rio Negro (MS). As zonas de amortecimento abrangem os rios Paraguai, Taquari, Cuiabá, Negro, Miranda todos pertencentes à Bacia Hidrográfica do Rio Paraguai.

A ciência cidadã tem sido marcante para a expansão do conhecimento científico (Bonney et al., 2009, p. 977) e sua constituição é multidisciplinar (Conrad e Hilchey, 2011, p. 283). Permite a participação ativa dos cidadãos em atividades científicas gerando experiência, compreensão e novos conhecimentos tanto para a ciência quanto para o cidadão participante (RIESCH; POTTER, 2014, p. 108, SULLIVAN et al., 2014, p. 32). Para Kruger e Shannon (2000, p. 462) a ciência cidadã é o processo pelo qual os cidadãos estão envolvidos na ciência como cientistas. No âmbito das ciências naturais Cohn (2008, p. 193), acredita que o termo cientista cidadão refere-se a voluntários que muitas vezes participam como assistentes de campo em estudos científicos, ajudando a monitorar a biodiversidade ou outros aspectos socioambientais, e constitui, em sua maioria, de cientistas leigos ou amadores que auxiliam nas pesquisas por amarem a natureza e a vida ao livre ou porque estão preocupados com as tendências ambientais e os problemas influentes e desejam contribuir na compreensão, reversão ou mitigação. Apesar de frequentemente não analisarem dados, nem redigirem artigos científicos, os cidadãos cientistas contribuem de maneira eficiente no levantamento de dados cooperando para responder a perguntas científicas e do mundo real (COOPER et al., 2007, p. 2, COHN, 2008, p. 193).

Para Lakshminarayanan (2007, p. 1), gestores de informações devem fazer uso de dados para produzir resultados científicos da mesma maneira que deveria ser permitido a qualquer cidadão. Para ele o foco da ciência cidadã não está nos cientistas tradicionais que utilizam os cidadãos como coletores de dados, mas a oportunidade de os cidadãos se comportarem como cientistas (LAKSHMINARAYANAN, 2007, p. 1). Além disso, a acessibilidade das

Revbea, São Paulo, V. 12, № 4: 153-164, 2017. 
informações deve estar adequadamente disponível ao público. Para Sullivan et al. (2014, p. 34), a ciência cidadã bem-sucedida envolve múltiplas ciências e não termina na coleta de dados, uma vez que o gerenciamento e a entrega de dados são igualmente fundamentais.

Cooper et al. (2007, p. 9) trazem a perspectiva urbano-residencial da aplicabilidade da ciência cidadã. Os mesmos concordam com vários autores sobre a abordagem da ciência cidadã como um método de integração de coleta de dados científicos que abrange grandes escalas geográficas e conta com a participação pública, no entanto, é dotada de flexibilidade que a permite operar em uma variedade de escalas temporais e espaciais, e pode ser utilizada para criar uma nova fronteira de atuação a fim de avançar teorias e práticas de conservação em ecossistemas urbanos. Há também a ciência cívica, bastante convergente aos conceitos de ciência cidadã e, talvez, pudesse ser tratada em paralelo da mesma. Para Kruger e Shannon (2000, p. 468), a ciência cívica busca entender o lugar como um sistema cultural que envolve a organização dinâmica, os simbolismos e, as pessoas, ao invés de meramente objetos de estudo, se tornam participantes do mesmo.

Uma outra face da ciência cidadã é quando o cientista, agora cidadão, comunica informações resultantes de sua pesquisa ao público geral, a fim de melhorar a compreensão, utilizando-se de linguagem acessível e de metodologias didáticas que facilitem a comunicação (RIESCH; POTTER, 2014, p. 109). Muitos esforços de cidadão cientista e de cientista cidadão têm contribuído para potencializar o levantamento de informações, de forma voluntária, sobre espécies e seus habitats. Essa interface entre ciência e cidadania, que comunica direitos e responsabilidades de uma sociedade, é interessante ser percebida e investigada. Se por um lado, o cientista possui formação e habilidades para a coleta de informações e exercício de todas as fases do fazer científico, a fim de manter a integridade científica, o mesmo não detém de todas as condições, oportunidades e possibilidades reais para reunir dados de forma abrangente e totalitária. Até porque, essa suposta supremacia não se revela interessante do ponto de vista da valorização da ciência e sua compreensão pública, uma vez que ao ser estimulada a participação social, a ciência ganha aliados e pode, finalmente, cumprir alguns dos seus objetivos, por exemplo, a conservação dos ambientes naturais e sua sociobiodiversidade e a construção de políticas públicas.

Seja como for, a ciência cidadã pode ser firmada com todo esforço entre cientistas, de múltiplos domínios científicos, que buscam acessibilizar conhecimento técnico-científico e agregar pessoas indistintamente, bem como entre cidadãos que desejam compreender o funcionamento dos processos naturais evidenciados pela ciência e oportunamente envolver-se com ela, visando, entre outros aspectos, conhecimento, entretenimento, bem-estar e a sua própria sobrevivência enquanto ser biológico e social.

Nas últimas décadas a revolução dos meios de comunicação e o crescimento impulsivo no uso de mídias digitais têm transformado o conceito de comunicação e impactado diretamente a vida social das pessoas. A 
criatividade humana na era digital expandiu o universo das redes sociais e seu progresso têm gerado ampla participação social em múltiplos contextos. No âmbito da conservação ambiental, direcionar o uso dessas tecnologias para o fortalecimento e melhor compreensão pública da ciência pode trazer motivação, interesse e benefícios mútuos, ao leigo e ao cientista ou instituição promotora da ação. Isto significa que ciência cidadã representa estratégia e oportunidade para promoção de vínculo com a natureza e seus elementos, comprometimento com sua proteção, aprimoramento e democratização do conhecimento.

Diante dessas perspectivas, este trabalho busca avaliar como o cidadão cientista e a ciência cidadã têm contribuído para o conhecimento e conservação da Reserva da Biosfera do Pantanal, identificando a capacidade de vivências na natureza, como as expedições ecoturísticas para observação de aves, em gerar interesse e colaboração com a ciência, e estimular posturas de conservação ambiental, bem como a participação e eficiência de algumas plataformas web colaborativas que buscam estimular a participação cidadã na construção de banco de dados, armazenamento e disponibilização de informações científicas ao público em geral.

\section{Metodologia}

Foram analisadas ações de ciência cidadã, tais como, o evento de expedição ecoturística para observação de aves "Busca ao Lifer - birding festival" e as plataformas colaborativas: Biofaces, Wikiaves, eBird e Táxeus, num recorte geográfico envolvendo a planície pantaneira e os planaltos adjacentes, os quais constituem a Reserva da Biosfera do Pantanal (Figura 1). O período de coleta de dados, tanto primários quanto secundários, compreendeu os anos de 2013 a 2015.

O evento Busca ao Lifer foi realizado nas seguintes Unidades de Conservação: Parque Nacional das Emas (2013), Reserva Particular do Patrimônio Natural Vale do Bugio (2014) e na Área de Especial Interesse Turístico (AEIT) Estrada Parque do Pantanal (2015). A atividade consistiu de etapas distintas, a saber: levantamento de dados primários em campo, foto recap (revisão de fotos e compartilhamento da experiência), socialização da vivência e dos lifers (primeiro encontro com uma espécie desconhecida e fruição da experiência), compilação do check list e análise dos dados.

Para o levantamento de dados secundários foram analisadas as plataformas colaborativas e autogestionadas sobre biodiversidade, quais sejam: Biofaces ${ }^{\odot}$, eBird ${ }^{\odot}$, WikiAves $^{\odot}$ e Táxeus $^{\odot}$. Para essa análise foi utilizada amostra temporal do período de 2013 a 2015 na região que abrange o Pantanal e os planaltos de entorno, à abrangência da Reserva da Biosfera do Pantanal. Dessas plataformas foram identificados dados como: temática abordada, número de cidadãos envolvidos, como contribui para a ciência na área de estudo e breve descrição de atuação. 


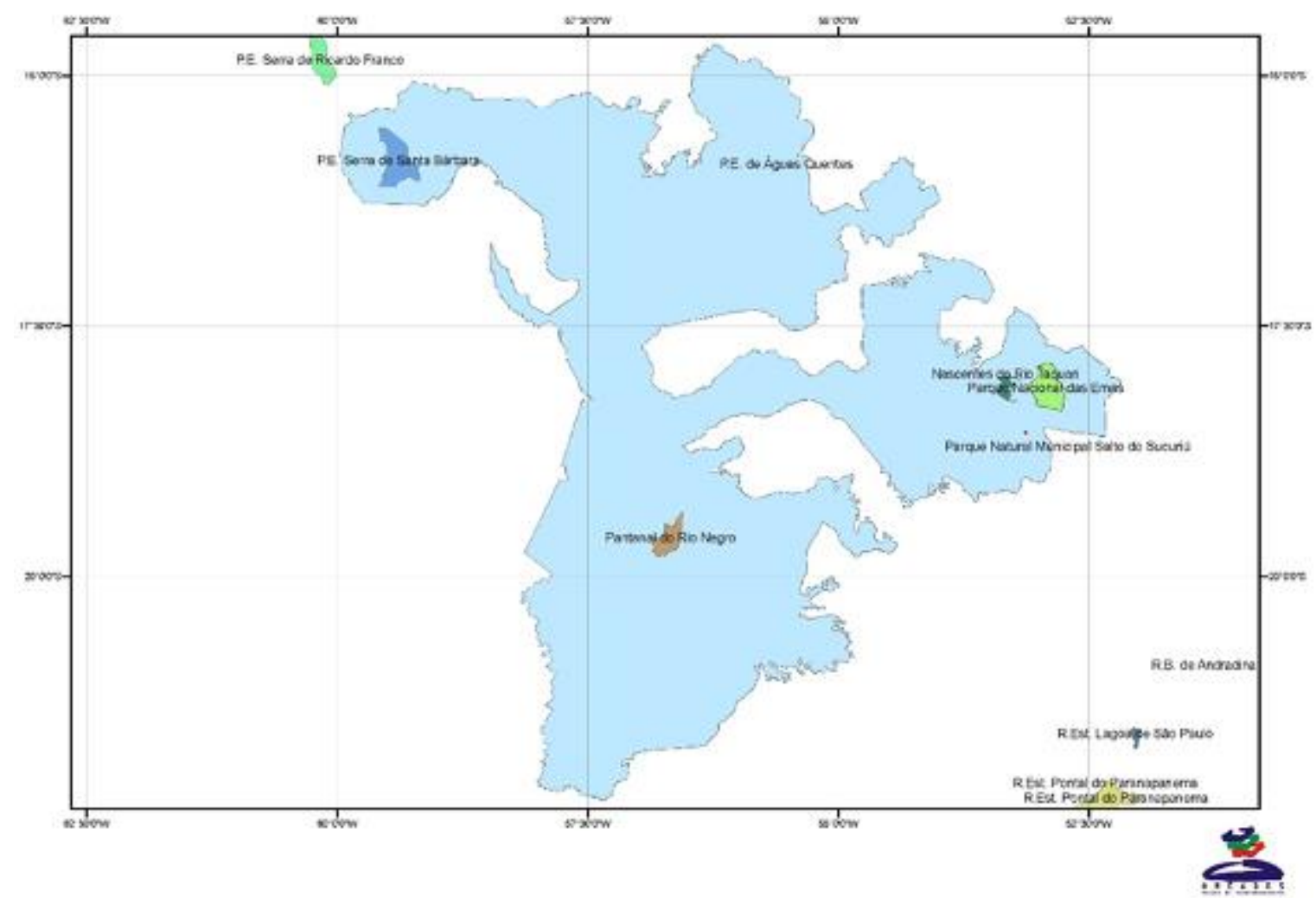

Figura 1: Mapa da Reserva da Biosfera do Pantanal. Fonte: Oréades Núcleo de Geoprocessamento, 2005.

\section{Resultados e discussão}

O Pantanal é um dos poucos lugares na região Neotropical onde a observação da fauna silvestre é amplamente favorecida, tanto em termos de riqueza quanto de abundância de animais, o que atrai muitos turistas, a exemplo de norte-americanos e europeus, interessados em oportunidades de atuação enquanto cidadãos cientistas contribuindo na coleta de dados em campo (EATON et al., 2017, p. 1). Assim, programas e projetos de conservação ambiental têm sido desenvolvidos no Pantanal e contam com a participação de voluntários. Não apenas protocolos de pesquisa têm sido aplicados com a participação desses voluntários, mas plataformas digitais e portais colaborativos, de origem nacional e internacional, têm conquistado pessoas do mundo todo a fim de colherem e disponibilizarem informações geradas por elas mesmas.

Com efeito, a ciência cidadã tem se apresentado como uma ferramenta de retroalimentação positiva na geração de conhecimento científico sobre a biodiversidade, congregando direitos e responsabilidades que se vinculam ao conceito de cidadania. (Figura 2). 


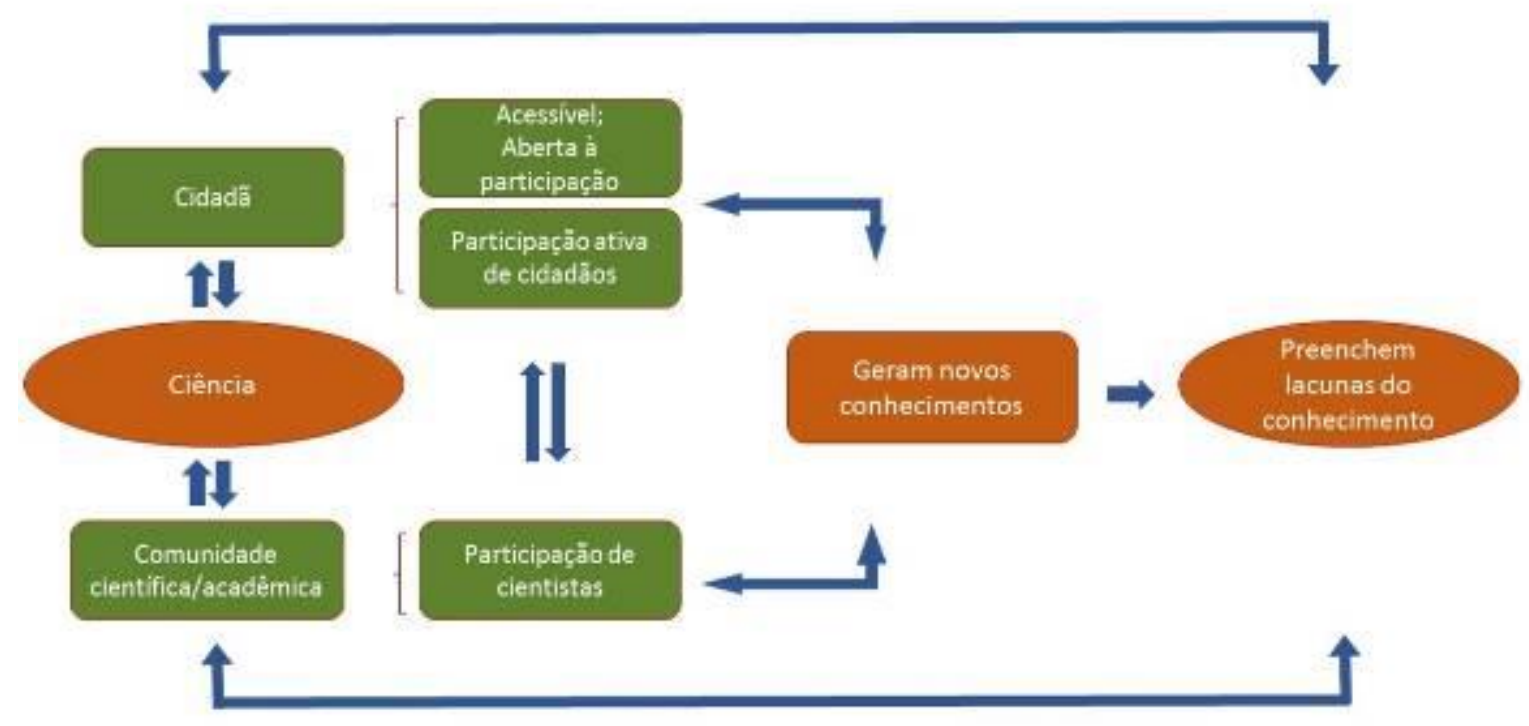

Figura 2. Fluxograma da Ciência Cidadã.

Nesse processo de constante retroalimentação, tanto o cidadão quanto o cientista profissional buscam gerar conhecimento a fim de torná-lo público, em âmbito formal ou informal, e preenchendo lacunas existentes. O que difere são os mecanismos utilizados para torná-lo público, a definição do público de interesse e o rigor requerido pela pesquisa, considerando o método científico, o tipo e a sistematização de dados coletados. Note-se que para ambos os atores, pessoas comuns e cientistas, a prática da cidadania é útil e aprimora os valores humanos, consequentemente, a ciência. No modelo de ciência cidadã o cidadão participante se percebe mais cientista, ainda que amador, e o cientista especializado se torna mais cidadão, processo este capaz de permitir maior aproximação da sociedade, reconhecimento e assimilação da ciência enquanto instrumento para políticas públicas, implicando retorno mais direto e evidente das pesquisas à sociedade e de forma mais compreensível pela população.

Busca ao Lifer - birding festival é uma atividade de observação de aves e de (re)conexão com a natureza, caracterizado como ecoturismo de experiência e instrumento de ciência cidadã, que promove vivências na natureza, conhecimento das espécies, educação ambiental e ecoturismo em ambientes naturais ricos em biodiversidade. As expedições tiveram como destinos a região do Parque Nacional das Emas (área núcleo da Reserva da Biosfera do Pantanal), Reserva Particular do Patrimônio Natural Vale do Bugio no planalto de entorno do Pantanal (borda leste) e Estrada Parque no Pantanal Sul. Como resultados destacam-se diversos registros de espécies de aves, na forma de documentação fotográfica e de listas de espécies, ambas disponibilizadas em plataformas colaborativas. O conhecimento adquirido, incluindo novos pensamentos e postura frente às questões socioambientais fazem dessa experiência ecoturística uma oportunidade para gerar empatia pela natureza, Revbea, São Paulo, V. 12, № 4: 153-164, 2017. 
interesse por temas científicos e para formação de pessoas enquanto agentes de proteção e conservação da biodiversidade.

Participaram do Busca ao Lifer, de 2013 a 2015, 32 pessoas de forma direta e mais de 500 indiretamente, a partir do uso e compartilhamento dos resultados (Tabela 1 ).

Tabela 1: Resultados das expedições Busca ao Lifer - birding festival de 2013 a 2015.

\begin{tabular}{|c|c|c|c|}
\hline Ano & Local & $\begin{array}{l}\text { Número de } \\
\text { participantes }\end{array}$ & Check List \\
\hline 2013 & $\begin{array}{l}\text { Parque Nacional das } \\
\text { Emas - Área Núcleo } \\
\text { da Reserva da } \\
\text { Biosfera do Pantanal }\end{array}$ & 08 & 115 espécies \\
\hline 2014 & RPPN Vale do Bugio & 12 & 93 espécies \\
\hline 2015 & $\begin{array}{l}\text { Estrada Parque do } \\
\text { Pantanal }\end{array}$ & 12 & 182 espécies \\
\hline
\end{tabular}

Pode-se dizer que as expedições para observação de aves têm se caraterizado também como uma tecnologia social que visa à sustentabilidade através do ecoturismo, o qual procura valorizar a sociobiodiversidade, fortalecendo os laços interpessoais, aprimorando o conhecimento do cidadão sobre a diversidade biológica do Pantanal e aproximando as pessoas aos diversos elementos da natureza, além de fomentar a valorização das Unidades de Conservação, espaços naturais muitas vezes desconhecidos do público (Figura 3).

Soma-se a esses resultados a contribuição à proposta de monitoramento participativo desenvolvida por projeto de pesquisa de pós-graduação intitulado "Conservação, grau de ameaça e monitoramento participativo da biodiversidade por meio do turismo da sub-região do Abobral no Sul do Pantanal brasileiro, vinculado ao Programa de Pós-graduação em Meio Ambiente e Desenvolvimento Regional da Universidade para 0 Desenvolvimento do Estado e da Região do Pantanal - UNIDERP. Dados do Busca ao Lifer foram decisivos para o sucesso dos resultados apresentados no projeto, tanto em decorrência do número de espécies de aves obtido quanto pela confiabilidade das informações, uma vez que os grupos são conduzidos por guias especializados e/ou especialistas em ornitologia. Programas de ciência cidadã precisam estar atentos à qualidade das informações geradas e as possibilidades de uso que elas representam, o que requer objetividade, acompanhamento e assistência de pesquisadores bem como comunicação entre estes e os cidadãos (TULLOCH et al., 2013, p. 133, SULLIVAN et al., 2014, p. 33). 


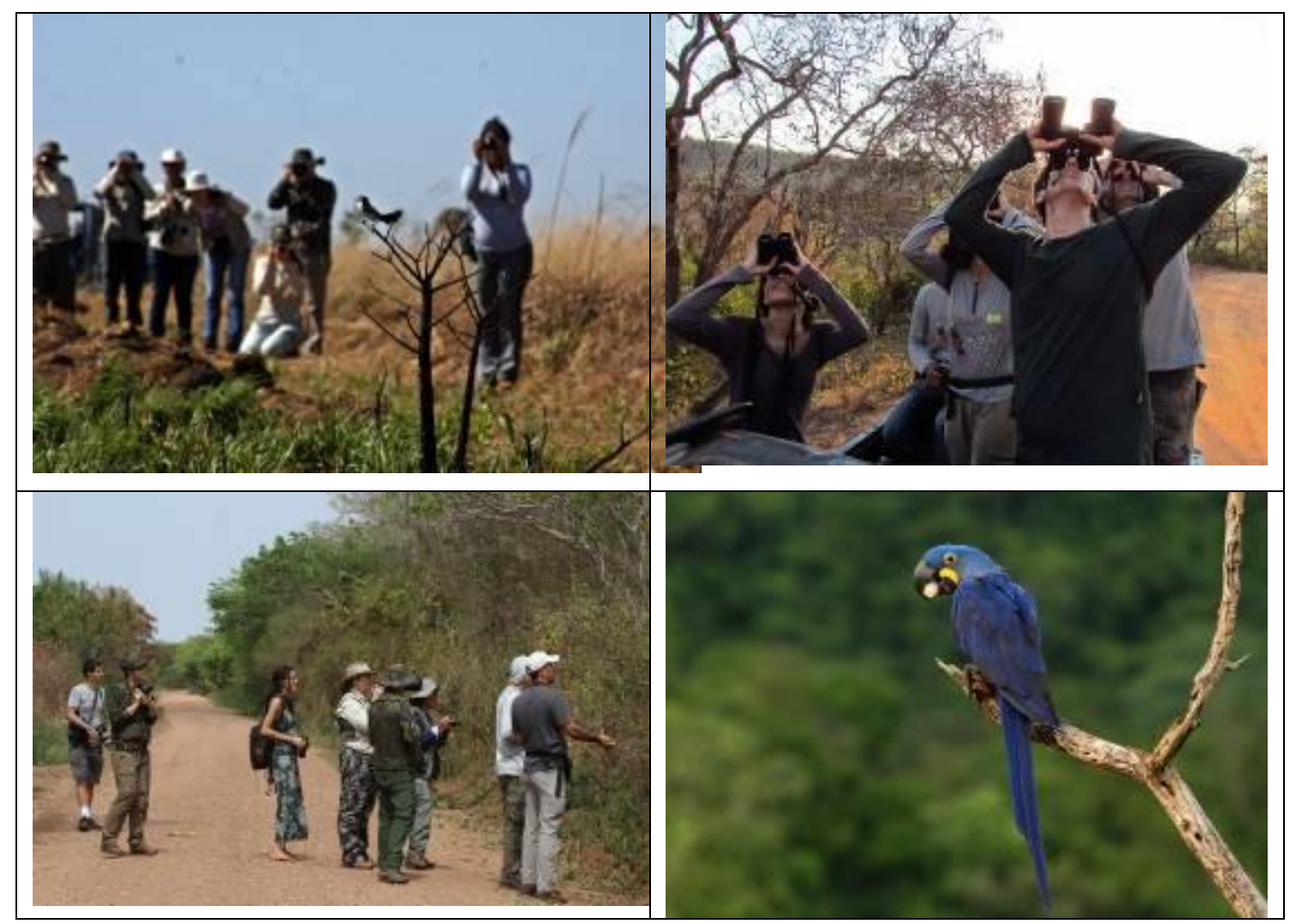

Figura 3: Registros fotográficos do I, II e III Busca ao Lifer, respectivamente na região da Reserva da Biosfera do Pantanal.

Sepúlveda (2016, p. 21) acredita que a inclusão de turistas em projetos de monitoramento permite que os mesmos contribuam ativamente na conservação da região, visto que seus relatos e disponibilização de registros fotográficos dos ambientes monitorados enriquecem a base de dados, além de auxiliar na melhor interpretação dos efeitos do turismo na biodiversidade a fim de torná-lo mais sustentável. A mesma opinião é compartilhada por Dickinson et al. (2010, p. 151), os quais observam que o atual modelo de ciência cidadã tem significativa influência em estudos ecológicos que envolvem o monitoramento da biodiversidade em grandes escalas geográficas, permitindo que pesquisadores façam inferências locais e regionais com o apoio dos cidadãos.

O público participante das expedições Busca ao Lifer durante os três anos foi constituído por pessoas de diversas áreas do conhecimento, com ou sem vínculo direto com as ciências naturais, por exemplo: educadores, pedagogos, biólogos, artistas, acadêmicos, condutores de visitantes, turismólogos, economista, engenheiros, guias de turismo, cozinheiros, empresários, cineastas, jornalistas, isto é, pessoas das mais diversas áreas unidas pela afinidade com o mundo natural e na busca do conhecimento, permitindo (re)conectar-se entre si e com os ambientes naturais. 
Das plataformas web avaliadas, observa-se o número significativo de participantes que as alimentam diariamente com informações sobre a temática da biodiversidade (Tabela 2).

Tabela 2: Descrição das plataformas interativas e seus respectivos resultados na região da Reserva da Biosfera do Pantanal.

\begin{tabular}{|c|c|c|c|}
\hline Plataforma & Tema & Descrição & $\begin{array}{c}\text { Resultados relativos } \\
\text { ao Pantanal }\end{array}$ \\
\hline Biofaces & Biodiversidade & $\begin{array}{l}\text { Consiste de uma rede social } \\
\text { desenvolvida para publicação de } \\
\text { fotos, sons, vídeos e estudos de } \\
\text { fauna, com o objetivo gerar } \\
\text { conhecimento da biodiversidade } \\
\text { e sua conservação. }\end{array}$ & $\begin{array}{l}\text { Número de usuários: } \\
2192 .\end{array}$ \\
\hline eBird & Aves & $\begin{array}{l}\text { Programa de check list online } \\
\text { com registros de aves, } \\
\text { documentando a presença ou } \\
\text { ausência de todas as espécies da } \\
\text { avifauna local, regional, nacional } \\
\text { e mundial. }\end{array}$ & $\begin{array}{l}\text { Mais de } 600 \text { espécies } \\
\text { registradas para a } \\
\text { região de Pantanal e } \\
\text { Planalto de entorno; } \\
1690 \text { listas submetidas } \\
\text { do MT, com } 560 \\
\text { espécies registradas; } \\
98 \text { listas do MS, com } \\
436 \quad \text { espécies } \\
\text { registradas. }\end{array}$ \\
\hline Táxeus & Biodiversidade & $\begin{array}{l}\text { plataforma colaborativa online } \\
\text { criada para suprir lacuna do } \\
\text { conhecimento. O gerenciamento } \\
\text { de listas de espécies da } \\
\text { biodiversidade brasileira pode ser } \\
\text { utilizada por leigos e especialistas } \\
\text { para fins de cadastramento, } \\
\text { manutenção e localização de } \\
\text { listas de espécies. }\end{array}$ & $\begin{array}{l}\text { Número de usuários: } \\
2158 ; \\
48 \text { Listas públicas de } \\
\text { aves referentes a } \\
\text { Pantanal e entorno; } \\
512 \text { espécies de aves } \\
\text { registradas; } \\
3 \text { listas públicas de } \\
\text { mamíferos, com } 49 \\
\text { espécies registradas. }\end{array}$ \\
\hline WikiAves & Aves & 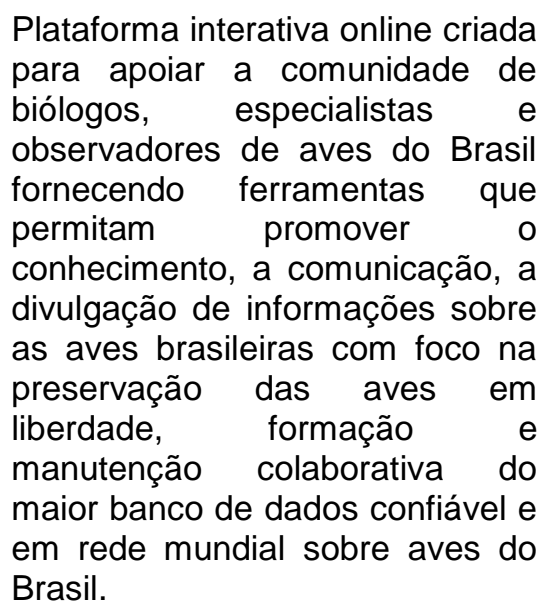 & $\begin{array}{l}\text { Número de usuários: } \\
25761 ; \text { registradas } \\
\text { Espécies para Brasil: 1861;) } \\
\text { Usuários de MT: } 389 ; \\
\text { Usuários de MS: } 379 ; \\
\text { Mais de } 600 \text { espécies } \\
\text { registradas para a } \\
\text { região de Pantanal e } \\
\text { Planalto de entorno. }\end{array}$ \\
\hline
\end{tabular}

Revbea, São Paulo, V. 12, № 4: 153-164, 2017. 
Eventos interativos como Aves do Natal e Big Day são incentivos para melhor conhecimento, mapeamento, fenologia e monitoramento da biodiversidade em caráter simultâneo, em escala regional e mundial, permitindo participação e sensibilização da comunidade nos processos de conservação.

Plataformas como o eBird, WikiAves, Biofaces e Táxeus têm contribuído em inúmeras pesquisas científicas permitindo estudos sobre estimativas de ocorrência, distribuição, movimentos migratórios e uma vasta quantidade de informações úteis à ciência e à sociedade em geral. Alguns elementos importantes devem ser considerados: a padronização da coleta de dados com protocolos claros, a simplificação operacional e o apoio técnico para que os participantes entendam o funcionamento, de modo a manter atrativa e constante essa participação (BONNEY et al., 2009, p. 980). O diálogo permanente e dinâmico entre cientistas especialistas e cientistas amadores pode maximizar os resultados de ações de conservação, gerando sentido de pertencimento, empoderamento, engajamento público e transformação social, com benefícios a todos os atores envolvidos. Cooper et al. (2007, p. 9) acreditam que combinando o poder da internet com uma população de cientistas cidadãos treinados pode ser uma oportunidade sem precedentes para mobilizar atores para 0 enfrentamento de novos problemas socioambientais.

É interessante notar que as plataformas supracitadas têm uma identidade cativante, principalmente sua capacidade e linguagem lúdica. Fazer os registros e publicizá-los ("postá-los") é também uma forma de entretenimento. Além disso, todas as ações ora apresentadas reforçam o aspecto significante da experienciação, a vivência na natureza, e sua capacidade estimuladora sobre os processos participativos. No entanto, fazer ciência não é algo apenas lúdico, embora o entretenimento possa representar importante elemento indutor para o interesse pela ciência. Huizinga (2010, p. 233) acredita que a civilização humana tem suas raízes no jogo, este com intensa função social, de modo que para atingir a plenitude de sua dignidade e estilo não pode deixar de levar em conta o elemento lúdico. Por isso quem promove a ações de ciência cidadã deve pensar que o entretenimento pode contribuir com a ciência, com a educação, na formação qualificada de cidadãos e promoção de políticas públicas. Além disso, nem tudo se limita ao universo digital e virtual, cada comunidade ou público tem um perfil, uma identidade, uma realidade, o que demandam ações estratégicas e linguagem específicas que gerem interesse e participação.

Assim, a ciência cidadã possui alto potencial para enfrentar problemas de significância continental podendo avançar em metas de conservação, com a possibilidade de criar uma cultura duradoura de mudanças de conduta e nas práticas de uso da terra resultando em melhorias a longo prazo (Cooper et al., 2007, p. 4) sob o enfoque da sustentabilidade. 


\section{Conclusões}

Projetos de ciência cidadã, no âmbito das ciências naturais, não são recentes no mundo, mas na atualidade tem-se experimentado estratégicas inovadoras de envolvimento da participação pública nos processos de alfabetização e investigação científica com significativos resultados para a educação ambiental. Isto significa que a ciência não pode ser reducionista, portanto não se resume à comunidade acadêmica. Assim, propostas que envolvem e estimulam a participação ativa de cidadãos podem trazer benefícios multilaterais para fins de conservação e sustentabilidade. Em análise dos resultados de expedições ecoturísticas para a observação de aves e das plataformas colaborativas é possível reunir evidências do comprometimento e apoio de cidadãos cientistas na geração de conhecimento sobre a biodiversidade regional vinculados ao exercício de cidadania e à transformação crítica de pensamentos e conduta, pilares importantes de uma educação ambiental crítica e transformadora.

\section{Referências}

BONNEY, R.; COOPER, C.B.; DICKINSON, J.; KELLING, S.; PHILLIPS, T.; ROSENBERG, K.V.; SHIRK, J. Citizen Science: a developing tool for expanding science knowledge and scientific literacy. BioScience, 59(11): 977-984, December/2009.

COHN, J.P. Citizen science: can volunteers do real research? BioScience 58(3) 192-197, March/2008.

CONRAD, C.C.; HILCHEY, K.G. A review of citizen science and communitybased environmental monitoring: issues and opportunities. Environmental monitoring and assessment 176:273-291, July/2010.

COOPER, C.B.; DICKINSON, J.; PHILLIPS, T.; BONNEY, R. Citizen science as a tool for conservation in residential ecosystems. Ecology and Society 12(2): 1-11, 2007.

EATON, D.P.; KEUROGHLIAN, A.; ANDRADE, M.C.A.S.; DESBIEZ, A.L.J.; SADA, D. W. Citizen scientists help unravel the nature of cattle impacts on native mammals and birds visiting fruiting trees in Brazil's southern Pantanal. Biological Conservation 208: 29-39, April/2017.

HUIZINGA, J. Homo ludens: o jogo como elemento da cultura. $6^{\underline{a}}$ ed. São Paulo: Perspectiva, 2010.

KRUGER, L.E.; SHANNON, M. A. Getting to know ourselves and our places through participation in civic social assessment. Society and Natural Resources 13: 461-478, 2000.

LAKSHMINARAYANAN, S. Using citizens to do science versus citizens as scientists. Ecology and Society 12:1, 2007. 
RIESCH, H.; POTTER, C. Citizen science as seen by scientists: methodological, epistemological and ethical dimensions. Public Understanding of Science 23(1): 107-120, January/2014.

SEPÚLVEDA, J.J.O. Conservação, grau de ameaça e monitoramento participativo da biodiversidade por meio do turismo da sub-região do Abobral no sul do Pantanal brasileiro. Dissertação de mestrado. UNIDERP, Programa de Pós-Graduação em Meio Ambiente e Desenvolvimento Regional, Campo Grande/MS, Setembro/2016.

TULLOCH, A.I.T.; POSSINGHAM, H.P.; JOSEPH, L.N.; SZABO, J.; MARTIN, T.G. Realising the full potential of citizen science monitoring programs. Biological Conservation 165: 128-138, May/2013. 